\begin{tabular}{|c|c|}
\hline \multirow{3}{*}{ 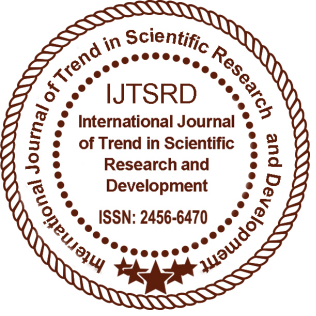 } & $\begin{array}{l}\text { International Journal of Trend in Scientific } \\
\text { Research and Development (IJTSRD) }\end{array}$ \\
\hline & International Open Access Journal \\
\hline & ISSN No: 2456 - 6470 | www.ijtsrd.com | Volume - 2 | Issue - 5 \\
\hline
\end{tabular}

\title{
Experimental Study on High Performance Concrete with Glass Fibre
}

\author{
Aqib Mohi Deen ${ }^{1}$, Mr. Shree Prakash ${ }^{2}$, Insha Altaf ${ }^{3}$ \\ ${ }^{1}$ Student, ${ }^{2}$ Guide, ${ }^{3}$ Co Guide \\ ${ }^{1,2}$ Department of Civil Engineering, \\ ${ }^{1,2}$ Al-Falah School of Engineering and Technology, Al-Falah University, Faridabad, Haryana, India \\ ${ }^{3}$ Niit Srinagar, Srinagar, Jammu and Kashmir, India
}

\begin{abstract}
In reviewing technology advances through the centuries, it is evident that material development plays a key role. Considerable efforts are still being made in every part of the world to develop new construction materials. In the construction industries, concrete technology is heading towards entirely new era by way of using glass fibre with high performance concrete.
\end{abstract}

Strength and durability are the two major factors to be considered in the design of structure subjected to static and dynamic loads. Characteristics of conventional concrete might not be entirely applicable to high strength concrete because of their difference in failure characteristics and engineering properties.

HPC is multi-componential interactive construction material. High strength is not only the parameter that has to be looked in the design of structural element. There are various other parameter such as modulus of elasticity, bond strength, flexural strength, and splitting strength etc. that tend to change the mechanical properties and failure characteristics of hardened concrete, expressive in the form of deflections, ultimate load, formation of cracks and crack pattern etc.

High performance concrete (HPC) is a specialized concrete designed to provide several benefits in the construction of concrete structures. The use of fibres in concrete has gained enormous popularity in the last decade. Studies have shown increasing evidence that the brittle behavior of HPC can be overcome by the addition of short Glass fibres of small diameter in the concrete mix. The present study aims to investigate the integration of Glass fibers with HPC of a designed mix of M60 grade of concrete. The influence of the cementations material dosage, cement/ultra-fine ratio, percentage of fibers, and the mixing procedures on the mechanical properties of concrete was studied by preparing several concrete mixes. Glass fibre specifically designed for use with concrete composites as admixture. Three different concentrations such as $0.75 \%, 1 \%$ and $1.25 \%$ of Glass Fibre by weight of cement were used. Glass fibre first dispersed in dry mix and surfactant using an ultrasonic mixer as per state-of-the-art techniques and then combined with water and high performance concrete. The various mechanical properties like Compressive, Flexural and Split tensile strength can be improved with the addition of low concentrations of Glenium ACE 30 in high performance fiber reinforced concrete.

Keywords: Opc Ordinary Portland Cement, Ggbs Ground Granulated Blastfurnace Slag, Fc Requird Strength Of Concrete, W/C Water-Cement Ratio, P Load, V Void Content Of Sand, Fcr Modulus Of Rupture

\section{INTRODUCTION}

In the world of civil construction engineering, concrete technology is heading towards entirely new era by the way of using polymers with super plasticizers in concrete. Increasing interest is being shown in the area of new materials in the past decades. This is quite understandable because, it is slowly, but increasingly being recognised that economic progress in the construction depends more 
on intelligent use of materials and constant improvement of available materials than on extreme reinforcement of structure.

Except steel structures, RC structures fracture in a brittle way or fail because of brittleness, because the ductilliness or deforming capacity of regular concrete is less. In these types of structures, the brittle failing is to in-elastic deforming capacity and it can be prohibited only if concrete is made to act in a more ductile way, so that the structural member can take in and evenly spread the high energy. The foresaid reasons attracted several researches and their investigation has provided in the development of new material like polymer composite concrete. Also the investigations have revealed that providing suitable confinement to concrete in compressive zone could further enhance the peak strength, strain at peak load and ductility of conventional reinforced concrete members. While several investigations are available in literature on strength and behaviour of HPC and polymer composites, attempt on polymer modified HPC, which reflects the combined effect of polymer and HPC on conventional concrete are scanty. Thus gap in the existing knowledge suggests that a present research program on the strength and ductility behaviour pattern of polymer modified HPC would be much relevance.

Therefore an attempt was made to study the experimentations, by adding the polymers in HPC on the strength aspects and behavioural aspect of concrete members under flexure.

\section{HIGH PERFORMANCE CONCRETE}

ACI defines HPC as "Concrete in which the performance and uniform necessity that cannot be always got adequately by only using regular materials and regular mixing, placing and curing practises". The necessities involved in the appraisal of characters such as placing and compacting without the segregation, early strength in the age in extreme environmental conditions, long term mechanical strength. Specialised mixing, placing of concrete, and curing of concrete practises are needed to produce and handling of high performance concrete. HPC is majorly being used in tunnels, bridges and tall structures for the strength, durability and high modulus in elasticity aspects. It is also being highly used in shotcrete repair, poles, parking, and garages.
HPC could be considered as high strength concrete if other attributes are satisfactory in terms of its intended application. Generally concrete with higher strength exhibits superiority of other attributes. In north American practise, high strength concrete is usually considered to be a concrete with 28 days compressive strength of at least $6000 \mathrm{psi}(42 \mathrm{Mpa})$. In a recent CEBFIP state of the art report of high strength concrete having a minimum 28 days compressive strength of 8700 psi (60Mpa). Clearly then the definition of high strength concrete is relative, it depends upon both the period of time in question and the location.

HPC is a concrete in which there is higher durability and higher strength comparatively with regular concrete. HPC contains more than one of the cementatious materials like silica fumes, GGBS, and is accompanied by any superplastisizer. The term high performance is important because the unique feature of that type of concrete is that its proportions are specifically taken as to have appropriate mechanical properties in the expected use of the structural member like high strength with low permeability. Therefore HPC is a special type of concrete. HPC contains the same material as that of the regular concrete. The use of many chemical and mineral admixtures such as silica fumes, super plasticizers, to enhance its strength, workability, durability, quality are at a very high extent.

It is necessary to pay careful attention to all aspects of concrete production (i.e. selection of materials, mix design, handling and placing). It cannot be emphasized too strongly that quality control is essential part of the production of high strength concrete and requires full cooperation among the materials or ready mixed suppliers, the engineer, and the contractor. In the essence then, the proportioning of high strength concrete mixtures consists of three interrelated steps:

Selection of suitable ingredients- cement, supplementary cementing materials, aggregates, water and chemical admixtures.

$>$ Determination of the relative quantities of these materials in order to produce as economically as possible, a concrete that has a desired rheological properties, strength and durability.

$>$ Careful quality control of every phase of the concrete making process. Recent developments in 
concrete technology have made it possible to produce concrete mixtures with strength properties that are beyond the strengths that are currently used by the structural design practise.

\section{DEVELOPMENT AND TECHNOLOGY OF HPC:-}

In 1950s, only natural aggregates (granites, sand, and gravel), ordinary Portland cements or slag-cements and water were used as constituents for concrete productions. W/C ratio was in the range of 0.60 to 0.70 and it was sufficient obtain good workability to the concrete. The compressive strength therefore was limited to about 20-40Mpa. In later 1970s, water reducing agents and super plasticizers were introduced into concrete production and using these, the W/C ratio was able to reduce about 0.45 to 0.55 without any negative effects on the concrete workability and strength. The compressive strength obtained was in the range of $60-70 \mathrm{Mpa}$.

Using high water reducing agent (HWRA) it was possible further reduction in W/C up to 0.25 and increase the strength up to $100 \mathrm{Mpa}$ was possible using mineral admixtures. Silica fume mineral admixtures which was the by-product of the Ferro silicon industries this product contains more than $90 \%$ silicon dioxide $\mathrm{SiO} 2$, and the particles are about 100 times finer than that of cement.

\section{DEFINITION OF HPC:-}

High performance concrete is also considered as high strength concrete. The word high strength concrete is a relative term. The definition of HPC varies both with the location and period of time. What is considered as a HPC in one country is regarded as normal strength in other countries. The definitions of HPC and HSC according to various institutions are as follows:-

\section{NEVILLE:-}

HPC is a concrete selected so as to fit for the purpose for which it is required. There is no mystery about it, no unusual ingredients are needed, and no special equipment has to be required. All we use is an understanding of the behaviour of the concrete and will, to produce a concrete mix within closely controlled tolerances.

\section{THE ACI COMMITTEE}

HPC as a concrete of normal weight aggregates having compressive strength for design of $41 \mathrm{Mpa}$ or greater shall not include concrete made using exotic materials or techniques.

The word exotic was included in the definition so that the committee would not be concerned with concretes such as polymer impregnated concrete, epoxy concrete or concrete with artificial, normal and heavy weight aggregates.

In 1993, the American concrete institute published the following definition:

"HPC is defined as the concrete which meets special performance and uniformity requirements that cannot always be achieved by using only the conventional materials and mixing, placing and curing practises. The performance requirements may involve enhancement of placement and compaction without segregation, long term mechanical properties, early age strength, toughness, volume stability, or service life in severe environments".

\section{ABRERA:-}

HPC as a concrete which is suitable for resisting deterioration in aggressive environments were water and chloride ions are freely available, and a concrete which will not require major repairs during its service life.

\section{STRATEGIC HIGHWAY RESEARCH PROGRAM SHRP-C-205: FOR PAVEMENT APPLICATIONS}

$>$ It shall have one of the following strength characteristics

- $4 \mathrm{hr}$ compressive strength $>17.5 \mathrm{Mpa}$

- $24 \mathrm{hr}$ compressive strength $>35 \mathrm{Mpa}$

- 28days compressive strength $>70 \mathrm{Mpa}$

It shall have a durability factor greater than $80 \%$ after 300cycles of freezing and thawing.

It shall have a water-cement ratio $<0.35$

\section{PAUL ZIA:-}

HPC is a concrete which meets special performance and uniformity requirements that cannot be always achieved by using the conventional materials and normal mixing, placing, and curing practices. The performance requirements may involve enhancement of placement and compaction without segregation, long term mechanical properties, early age strength, toughness, volume stability, service life and durability. 


\section{R. N. SWAMY:-}

A high performance concrete element is that which is designed to give optimised performance characteristic for a given set of load, usage and exposure condition, consistent with requirement of cost, service life and durability.

\section{PROPERTIES OF HIGH PERFORMANCE CONCRETE:-}

High performance concrete is characterized by special performance both short term and long term and uniformly in behaviour. Concrete must be proportioned to carry imposed loads, resist deterioration and be dimensionally stable. The quality of concrete is characterized by its mechanical properties and ability to resists deterioration.

The main parameters to be considered in determining high performance are;

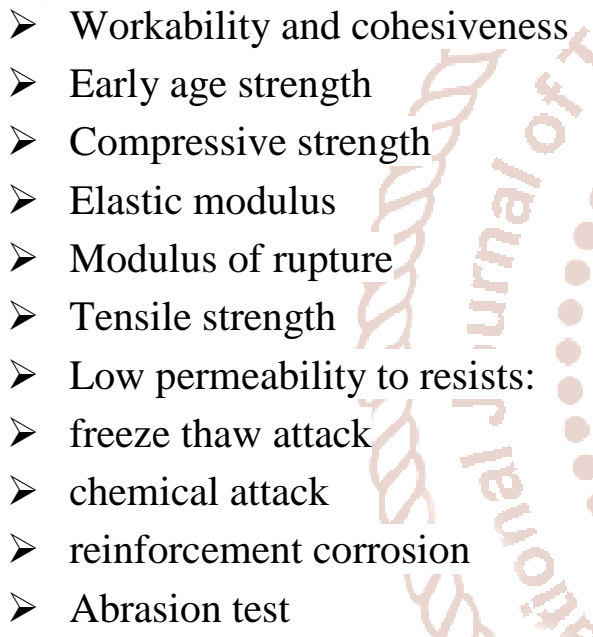

\section{EARLY AGE STRENGTH:-}

Traditionally, interest in the strength and other properties of concrete has been focused on those at 28days and beyond. In the past several years, there has been an increasing interest in the strength and other properties of concrete at ages less than 28days. There are at least three factors which have contributed to this increased interest in early strength:

The fast placed construction schedules that exposed concrete to significant structural loads at early ages,

$>$ The development of speciality cementsor admixtureswhich enable the achievement of higher strength at early ages, and

$>$ The recognition that long term performance of concrete is greatly affected by its early age history.
Early stage properties of concrete are important because of the significant construction loads that structures can be subjected to in the first few days after placement. They are also significant as they impact on its long term performance.

The properties of concrete develop as a result of hydration namely, the exothermic reactions between water and cement and the interaction with the other pozzolanic cementatious components in the mix.

\section{COMPRESSIVE STRENGTH:-}

Concrete compressive strength in particular is widely used in specifying, controlling and evaluating concrete quality. The strength of concrete depends on number of factors namely,

$>$ Water cement ratio \& water binder ratio

- Mechanical properties of coarse aggregate

$>$ Compaction energy or degree ofcompaction

Aggregate cement ratio

$>$ Optimum percentage of silica fumes

7 Curing methods

$>$ Degree of hydration

$>$ Rate of loading

Method of testing and

Specimen geometry

The cement replacement materials like silica fume, etc. Has an accelerating effect on the early hydration of Portland cement as it reduces the retarding effect of lignosulfonate retarders. At standard curing conditions, its contribution as a pozzolona to compressive strength occurs in the first 4-7 days.

\section{TENSILE STRENGTH:-}

The tensile strength governs the cracking behaviour and affects other properties such as stiffness, damping action, bond to embedded steel, and durability of concrete. It is also of importance with regard to the behaviour of concrete under shear loads. The tensile strength is determined either by direct tensile tests or by indirect tensile tests such as flexural or split cylinder tests.

The split tensile strength as recommended by ACI committee 363 is given by, ........... 
The effect of prior compressive loading on the split tensile strength was investigated by liniers and concluded that limiting the compressive stresses to $60 \%$ of the strength is essential if only tolerable damage is to be accepted.

\section{FLEXURAL STRENGTH OR MODULUS OF RUPTURE:-}

Flexural strength or modulus of rupture is measured by a beam flexural test and is generally taken to be a more reliable indicator of the tensile strength of concrete. If is often assumed that flexural strength of concrete is about $15 \%$ of the compressive strength.

The modulus of rupture may be estimated by....

Shah \& ahmed proposed the following equation, to predict the average split tensile strength for concrete up to $84 \mathrm{Mpa} . . . . . . .$.

\section{MODULUS OFELASTICITY:-}

The static modulus of elasticity can be expressed as secant, chord or tangent modulus. According to the ACI building cone (ACI-318-89), it is defined as the ratio of the stress at $45 \%$ of the strength to the corresponding strain. Static, chord modulus of elasticity, as determined by ASTM C469, is defined as the ratio of the difference of the stress at $40 \%$ of the ultimate strength. The modulus of elasticity of the aggregate the higher the modulus of the resulting concrete. The shape of the coarse aggregate particles and their surface characteristics may also influence the value of the modulus of elasticity of concrete.

\section{POISSONS RATIO:-}

Poisons ratio under uniaxial loading conditions is defined as the ratio of lateral strain to strain in the direction of loading. The poisons ratio of higher strength concrete in the elastic range appears comparable to the expected range of values for lower strength concrete. In the inelastic range, the relative increase in lateral strains is less for higher strength concrete. That is HSC exhibits less volume dilation than lower strength concrete. This implies less internal micro cracking for concrete of less strength.

Experimental data is limited on this aspect but based on available experimental information; poisons ratio is close to 0.20 regardless of compressive strength or testing age for both normal \& high strength concrete.

\section{SHRINKAGE}

Shrinkage is the decrease of concrete volume with time. This decrease is due to changes in the moisture content of the concrete and physio chemical changes, which occur without stress attributable to actions external to the concrete.

The key factors affecting the magnitude of shrinkage are:

Aggregate, w/c ratio, member size, medium ambient conditions, admixtures, carbonation, cements type.

Shrinkage of high performance concrete may be expected to differ from conventional concrete in three bond areas: plastic shrinkage, autogenous shrinkage and drying shrinkage.

\section{CREEP:-}

Creep is time dependant increase of strain of hardened concrete subjected to sustained stress. Ngab et al., found little difference between the creep of HSC under drying and sealed conditions. Similar to NSC, the creep in HSC is reported to decrease at the age at loading increases \& a linear relationship with the applied stress wasobserved.

On the basis of the investigations of smartdietal, ACI $363 \mathrm{R}$ indicated that HSC has a specific creep of only about $20 \%$ that of lower strength concrete and a creep coefficient about $30 \%$ ashigh.

\section{PERMEABILITY:-}

One of the main characteristics of high performance concrete compared to that of normal strength concrete is the more uniform and homogenous microstructure. When the Portland cement is combined with the ultra fine particles of silica fumes in low w/c ratios, the microstructure of such system consists mainly of poorly crystalline hydrates forming a more dense matrix of low porosity.

\section{FROST RESISTANCE:-}

Okada et al. reported very good frost resistance of non air entrained high performance concrete with w/c ratios in the range of $0.20-0.35$.

Foy et al observed that the resistance to salt scaling of concrete with a w/c ratio of was very good even after 150cycles. 


\section{CHEMICAL RESISTANCE:-}

Chemical resistance on concrete results in destructive expansion and decomposition of the cement paste leading to severe deterioration.

According to Mehta the water content of 0.33-0.35 gave too low permeability to cause any deterioration. In more aggressive environments pure Portland cements have shown some deterioration, whereas addition of silica fumes has given practically unaffected performance.

\section{ABRASION RESISTANCE:-}

Abrasion is wearing due to repeated rubbing and friction. For pavements, abrasion results from traffic wear. Adequate abrasion resistance is important for pavements and bridges decks from the standpoint of safety. Excessive abrasion leads to an increase in accidents as the pavement becomes polished reducing its skid resistance.

Mechanical abrasion is the dominant abrasion for pavement and bridge decks exposed to studded tires. The experiment conducted at Norway 1985 concluded that by increasing the strength from 50Mpa to $100 \mathrm{MPa}$ the abrasion of the concrete was reduced roughly $50 \%$. At $150 \mathrm{Mpa}$ the abrasion of concrete was reduced to the same low level as that of quality massive granite, this represents an increased service life of the highway pavement by a factor of approximately ten when compared to that of a high quality asphalt pavement.

\section{POLYMERS IN CONCRETE:-}

Generally there are three major types of polymer concrete containing polymers which are polymer impregnated concrete (PIC), polymer cement concrete (PoCC) and polymer concrete (PC). Polymer concrete is a concrete containing composite polymer as a primary binder instead of ordinary Portland cement polymer impregnated concrete is generally a precasted concrete in which it is dried and then evacuated and later impregnated with low viscosity monomer or mixture of many monomers that polymerize in the outside field to form the network of polymers within the porous system. Impregnation results are marked with improved higher strength and higher durability with comparison of ordinary concrete.

Polymer modified concrete (PMC) or polymer Portland concrete (PoCC) is modified cement concrete where the part of cementatious binder is changed by synthetic organic polymer. It is made by introducing a monomer, a pre polymer monomer mix, or dispersed polymer (latex) into ordinary Portland cement concrete.

Amongst these three, PMC or PPCC is most widely used because of its relatively lesser cost and is quite similar in processing technology to that of ordinary concrete.

\section{BACKGROUND AND HISTORY OF HPC AND POLYMER CONCRETE:-}

Credit of the word high performance concrete will go to the French people. The terminology was done in 1980 by roger lacroix and an yves malier. In the year 1986, the French project "new year ways of concrete "was brought together by 36 researchers comprising of france, Canada and Switzerland. Heading the Canadian group was a scientist pierre claude aitcin. Their research, finding of results and field applications of members of this group coined the contents of the initia 1 book published that solely devoted to HPC (malier, 1990). Then later on as technology advanced, polymer concrete was invented and many researches have been made in this area and it has given successful results in terms for better performance, durability, impermeability etc. hence now a days polymer concrete is opted in most of the constructions.

\section{OBJECTIVES OF PROJECT:-}

In the construction industry, concrete technology is heading towards an entirely new era by way of using polymers with super plasticizers in concrete. Increasing interest is being shown in the area of new materials in the past decade. This is quite understandable because, it is slowly, but increasingly being recognised that economic progress in construction depends more on an intelligent use of the materials

Composite materials are increasingly gaining immense popularity due to their high specific strength and density. Their ability to be tailored according to the purpose has given them an edge over the conventional materials like metals, polymers and ceramics. It has been understood from the literature that many of properties of engineering such as tensile and compressive strength, flexural strength, fractural strength, energy absorption capacity, impactness resistance etc., of the conventional concrete could be 
improved by the addition of latex on the strength and durability behaviour over conventional concrete.

Nowadays, the research on cementatious matrix materials is targeted on additives, polymers and admixtures. These are to improve a certain number of properties physically and mechanically, with keeping its strength, at economical cost and durability, viscous damping and fire performance are few of the important research lines in the cementatious matrix materials.

Glass fibre (GFRC) is similar to chopped fiberglass (the kind used to form boat hulls and other complex 3d shapes), although much weaker. Its made by combining the mixture of fine sand, cement, polymer (usually an acrylic polymer), water other admixtures and alkali resistance (AR) glass fibre. Many mix design are available online, but you'll find that al share similarities in the ingredients and proportions used.

GFRC is a type of concrete which basically consists of a cementitious matrix composed of cement, sand, coarse aggregate, water, polymer, and admixtures, in which short length glass fibre are dispersed. In general, fibres are the principle load carrying members, while the surrounding matrix keeps them in the desired locations and orientations, acting as a load transfer medium between the fibres and protecting from them environmental damage. Infact the fibres provide reinforcement for the matrix and other useful functions in fibre reinforced composite materials.

\section{SOME OF THE BENEFITS OF GFRC INCLUDES:}

$>$ ABILITY TO CONSTRUCT LIGHTWEIGHT PANELS:- Although the relative density is similar to concrete, GFRC panels can be much thinner than traditional concrete panels, making them lighter.

$>$ HIGH COMPRESSIVE, FLEXURAL, AND TENSILE STRENGTH:- The high dose of glass fibre leads to high tensile strength while the high polymer content makes the concrete flexible and resist into cracking. Proper reinforcing using scrim will further increase the strength of objects and is critical in projects where visible cracks are not tolerable.
STRUCTURE OF REPORTS:-

The report consists of total five chapters;

CHAPTER 1:- Gives a brief introduction to the investigation carried out, background of HPC and GLASS FIBRE.

CHAPTER 2:- Explain the literature survey of research work carried out by different investigations on HPC, GLASS FIBRE, and on flexural members of concrete. Towards the end of the chapter need for present investigation is discussed in detail.

CHAPTER 3:- Deals with the material used in test specimens, experimental program, test setup and detailed description of the test procedure.

CHAPTER 4:- Deals with the tests results and discussion of experimental investigations on the flexural behaviour of HPC and polymer (GLASS FIBRE) reinforced concrete beams during the course of experimental studies.

CHAPTER 5:- Deals with summary and conclusion derived from the above study.

CHAPTER 6:- Deals with reference for above studies.

\section{LITERATURE REVIEW}

In this chapter, an eloborative discussion is made regarding works done so far in this area as literature review. Fibre reinforced concrete with different fibres and their behaviour studies are discussed at the initial subheadings. Works on waste materials are discussed in the subsequent headings comprehensively.

\section{REVIEWS ON FIBRE REINFORCED CONCRETE}

\section{History and Development}

The concept of using fibres in a brittle matrix was first recorded with the ancient Egyptians who used the hair of animals and straw as reinforcement for mud bricks and walls in housing. This dates back to 1500 B.C. (Balaguru et al, 1992).

Ronald F. Zollo (1997) presented an overview regarding the history and development of Fibre Reinforced Concrete 30 years ago. According to this 
report, in the early 1960s, the works on fibre reinforced concrete had been started. A lot of research work has been conducted by many researchers on different fashions. But these projects have studied about steel fibres alone. So far, there were only a few works which have studied the other fibres like nylon, plastic, rubber and natural fibres. But those researches are completely different from the current study, since they have concentrated along the material strength properties not on their structural behaviour.

According to the terminology adopted by American Concrete Institute (ACI) Committee 544, there are four categories of Fibre Reinforced Concrete namely 1) SFRC (Steel Fibre Reinforced Concrete), 2) GFRC (Glass Fibre Reinforced concrete), 3) SNFRC (Synthetic Fibre Reinforced Concrete) and 4) NFRC (Natural Fibre Reinforced Concrete). It also provides the information about various mechanical properties and design applications. Cement and Concrete Institute also published the classification of FRC in their website. Based on their classification, Fibres are classified into Glass, Steel, Synthetic (includes Acrylic, Aramid, Carbon, Nylon, Polyster, Polyethylene, Polypropylene) and Natural Fibres.

\section{Mechanical Properties}

Kukreja et al (1980) conducted some experiments and reported that, based on the results of three methods such as split tensile test, direct tensile test and flexural test, split tensile strength test was recommended for fibrous concrete. Also increase in tensile strength and post cracking strength, toughness were reported.

Researchers like Goash et al (1989) studied tensile strength of SFRC and reported as inclusion of suitable short steel fibres increases the tensile strength of concrete even in low volume fractions. Optimum aspect ratio was found as 80 and the maximum increase in tensile strength was obtained as $33.14 \%$ at a fibre content of $0.7 \%$ by volume. Also it was reported that cylinder split tensile strength gave more uniform and consistent results than the modulus of rupture test and direct tension test.

Sabapathi and Achyutha (1989) stress - strain characteristics of steel fibre reinforced concrete under compression. Cube compressive strength and Initial Tangent Modulus of Elasticity were obtained and equation for stress-strain relation was also proposed.
Distribution and orientation of fibres in FRC significantly affects the properties of FRC. Based on this concept, Paviz Soroushian and Cha-Don Lee (1990) have carried out some investigation, by counting the number of fibres per unit cross sectional area of SFRC specimen incorporationg various volume fractions of different fibres. Theoretical expressions were derived for the number of fibres per cross sectional area in fibre reinforced concrete as a function of volume fraction and length, assuming the cross sectional boundaries as the only factors distributing the 3-D random oriention of fibres. They made comparisons between number of fibres per cross sectional area and the reorientation fibres in concrete due to vibration.

To ascertain the tensile strength of fibre reinforced concrete, a simple test set up was introduced to replace the costly direct tensile strength test apparatus by Youjiang Wang et al (1990). Methodology and testing procedure were also given. But it requires a servo controlled testing machine.

Ganesan and Ramana Murthy (1990) ascertained the stress - strain behaviour of short, confined, reinforced concrete column with and without steel fibres. The volume fraction of $1.5 \%$ with aspect ratio of 70 of steel fibres was used. The variable of the study was percentage reinforcement of lateral reinforcement. The strain at peak loads was increased to certain extent.

Ziad Bayasi and Paviz Soroushian (1992) reported that the rhelogical properties of SFRC are significant. The large surface area and interlocking property of fibres lead to the formation of balls among the concrete during mixing which can create damage to the hardened material properties. An experimental investigation was conducted by them to study the fresh concrete properties of concrete with different types of steel fibres. It was concluded that the fresh concrete workability preoperties of FRC were significantly affected by fibre reinforcing index. At a specific fibre reinforcing index, crimpled fibres seem to give slightly higher value than plain fibres.

Balaguru and Shah (1992) have reported that the fibres that are long and at higher volume fractions were found to ball up during the mixing process. The process called 'bal ing' occurs and causes the concrete 
to become stiff and a reduction in workability with increase volume dosage of fibres. This has a tendency to influence the quality of concrete and strength.

Mechanical properties of high strength fibre reinforced concrete were also studied by Faisal $\mathrm{F}$ Wafa and Samir A. Ashour (1992). They tested 504 test specimens for different mechanical properties such as compressive strength, split tensile strength, flexural toughness and modulus of rupture. The mix was designed to achieve compressive strength of 94 $\mathrm{N} / \mathrm{mm} 2$. Three volume fractions of steel fibres such as $0.5 \%, 1.0 \%$ and $1.5 \%$ were selected. It was concluded that no real workability problem was encountered upto the addition of $1.5 \%$ volume fraction of fibres in concrete. Steel fibres enhanced the ductility and post cracking load carrying capacity of high strength concrete. Some emprical relations were proposed in terms of volume fraction of fibres and compressive strength of conventional concrete.

Similar to the studies on steel fibre reinforced concrete, some researchers have also been carried out by the researchers on synthetic fibre reinforced concrete. Ziad Bayasi and Jack Zeng (1993) conducted some experiments on workability and mechanical strength properties. Fibrillated polypropylene fibres of length $1 / 2$ inch and $1 / 4$ inch at three volume fractions, $0.1,0.3$ and $0.5 \%$ were used in concrete and workability properties such as slump, inverted slum cone, air content and mechanical strength properties such as compressive, impact and flexural behaviour were studied. In addition rapid chloride permeability was also conducted. The impact test was conducted according to ACI Committee 544 method. A number of blows required to fail the cylindrical specimen were placed below a height of $457 \mathrm{~mm}$. The hammer weight was about $45.5 \mathrm{~kg}$. From this extensive research work, it was concluded that polypropylene fibres have no detectable effect on workability up to $0.3 \%$. Permeability of concrete was increased due to the addition of polypropylene fibres. Similarly post - peak flexural strength and impact resistance also increased due to the fibre addition.

Kumar et al (1997) made a study on statistical prediction of compressive strength of steel fibre reinforced concrete and they reported that the compressive strength of SFRC increased steeply with the increase of fibre content up to $1 \%$ (by volume) and beyond which the rate of increase in strength reduced. It was also reported that the compressive strength of GFRC increases with the increase in the aspect ratio upto 60 and beyond this the rate of increase in strength reduces. It was further concluded that Fibre Reinforcing Index (FRI) significantly influences the compressive strength and the strength increased up to FRI $=90$ for straight fibres and FRI = 60 for crimpled fibres. Beyond these values, the rate of increase in strength started to decrease. They also proposed some statistical empirical relationships between compressive strength and FRI.

Nataraja et al (1998) conducted a study on steel fibre reinforced concrete under compression. Here the behaviour of steel fibre reinforced concrete under compression for cylinder compressive strength ranged from 30 to $50 \mathrm{~N} / \mathrm{mm} 2$. Round crimpled fibres with three volume fractions of 0.5 percent, 0.75 percent and 1.0 percent and for two aspect ratios of 55 and 82 are considered. The effect of fibre addition to concrete on compressive strength was studied. It was concluded that the addition of fibres increased the compressive strength and toughness. Some empirical equations were also proposed for compressive strength of concrete in terms of fibre reinforcing index.

Rami H. Haddad and Ahmed M. Asteyate (2001) found an interesting way of predicting the role of synthetic fibres such as polypropylene and nylon fibres in delaying steel corrosion cracks and improving the bond with concrete. Different lengths of polypropylene and nylon fibres with various volumes were mixed with concrete. Pullout tests and corrosion study were conducted and they were concluded that both the fibres contributed more in delaying the corrosion and improving the bond strength. Moreover it was pointed out that polypropylene fibres played more significant role than nylon fibre in the improvement of bond.

Another intresting investigation was carried out by Yaghoub Mohammadi and Kaushik (2003) about the effect of mixed aspect ratio of fibres on mechanical strength properties of concrete. $25 \mathrm{~mm}-50 \mathrm{~mm}$ long crimped type flat steel fibres were mixed in different proportions with concrete and tested for split tensile, compressive and static flexural strength. Compressive toughness and flexural toughness were obtained from the test results. It is found that $65 \%$ of long fibres and $35 \%$ of short fibres gave the optimum composite properties when compared with other mixes. An important note also was given in that literature that 
use of mixed aspect ratio of fibres does not have a significant effect on the static modulus of elasticity.

$\mathrm{Wu}$ Yao et al (2003) examined the mechanical behaviour of hybrid fibre reinforced concrete at low fibre volume fraction. Three hybrid composites such as polypropylene and carbon, carbon and steel and steel and polypropylene fibres were chosen and the mechanical strength properties such as Compressive strength, split tensile strength, modulus of rupture and flexural toughness were ascertained. A statistical response surface method and three level full factorial experimental designs were used to study the effects of volume fraction and aspect ratio of fibre on fractional energy, compressive strengh, splitting tensile strength, flexural strength and characteristic length of steel fibre reinforced concrete.

Job Thomas and Ananth Ramasamy (2007) performed some experimental investigations on mechanical properties of steel fibre reinforced concrete. Three different strengths such as normal strength (35 MPa), moderately high strength (65 Mpa) and high strength (85 Mpa) concrete mixes were selected for this study. A $30 \mathrm{~mm}$ long steel fibres (aspect ratio of 55) with three different volume fractions as $0.5 \%, 1.0 \%$ and $1.5 \%$ were selected and uniformly distributed in the mix. The mechanical strength properties such as compressive strength, split tensile strength, modulus of rupture and post cracking performance, modulus of elasticity, poisson's ratio and strain corresponding to peak compressive stress were studied. Based on 60 test data regression analysis is done and empirical relations were provided.

Based on the test results of 320 specimens of mechanical strength properties of high strength fibrous concrete, Premalatha and Sundararajan (2007) suggested that no significant improvement in compressive strength was obtained beyond $1.5 \%$ volume fraction of steel fibre content. The high strength concrete mixwas designed to achieve 60 $\mathrm{N} / \mathrm{mm} 2$ and its strength properties like compressive strength, modulus of rupture, split tensile strength were studied and empirical relations were also proposed in terms of Fibre Reinforcing Index (FRI) The effects of aspect ratio and volume fractions of steel fibre on the mechanical properties of SFRC were studied by Semsi Yazici et al. (2007). Three aspect ratios (1/d) of 45, 65, 80 and three volume fractions of $0.5 \%, 1.0 \%, 1.5 \%$ hooked end bundled fibres were taken in that study. It showed an increase in the aspect ratio decreased the workability; in compressive strength, $4-19 \%$ increase; in split tensile strength 11 - 54\% increase and in flexural strength $3-18 \%$ increase were obtained from the experimental investigation. A multilinear regression analysis was also studied.

\section{FIBRE REINFORCED CONCRETE BEAMS UNDER STATIC LOADING}

Lakshmipathy and Santhakumar (1987) conducted an experimental analytical investigation on two span continuous beams with steel fibres. The important characteristics such as cracking behaviour, ductility and energy absorption were ascertained from experimental investigation and compared with analytical results. The fibrous concrete beams served to be superior to conventional concrete.

Rao et al (1987) conducted an experimental investigation on deformation characteristics and strength of reinforced concrete beams made with steel fibres in pure bending. A number of beams each with $1.85 \mathrm{~m}$ span were cast and tested under static flexural loading. The increase in depth of neutral axis and hence flexural stiffness of fibre reinforced concrete beams at all stages of loading reflected the ability of fibres in arresting the crack growth. The inclusion of steel fibres in the concrete significantly increased the post cracking stiffness at all the stages up to failure.

Lim et al (1987) carried out some experimental and analytical study on bending behaviour of steel fibre reinforced concrete beams. A simplified MomentCurvature $(\mathrm{M}-\varnothing)$ relationship for beam with rectangular shape was proposed. The proposed model was verified with experimental results that carried out $\mathrm{m}$ span reinforced concrete beams. The enhancement in ductility and energy absorption under static loading was reported through the study.

Balaguru and Shah (1992) reported that the modern developments of using only straight steel fibres began in the early 1960's. Til now, a wide range of other type of fibres was used in cement matrices. Construction industries have contributed to the development of conventional fibres such as steel, stainless steel and glass.

Cheng-Tzu Thomas Hsu et al (1992) were presented a computer algorithm to analyse the load - deflection and moment - curvature behaviour of steel fibre reinforced concrete beams. A total of 11 SFRC simple 
beams were cast and tested under two point loading. The experimental results obtained were compared with computer program results.

Dwarakanath and Nagaraj (1997) examined the flexural behaviour of fibre reinforced concrete beams. In this study, fibres were put in two types of locations such as over the entire depth and over half the depth of the beam on the tension side. They tested 20 numbers of $1.8 \mathrm{~m}$ long reinforced concrete beams with steel fibers, under flexural static loading. Midspan deflections and curvatures at salient points such as cracking, and ultimate points were compared. It is found that half the depth mode of inclusion of fibres for under reinforced concrete beams and full depth mode of inclusion of fibres for over reinforced concrete beams.

Antonia F. Barbosa and Gabriel O. Ribeiro (1998) worked on ANSYS for finite element analysis of reinforced concrete structures. A simply supported reinforced concrete beam subjected to uniformly distributed load was taken as a simple example in that study. Two different models were considered for steel reinforcement such as discrete and smeared. Load deflection curves obtained through ANSYS have been compared with experimental results and they have been found to be satisfactory.

Piti Sukontasukkul (2004) conducted an experimental investigation on toughness of steel and polypropylene fibre reinforced concrete beams under bending using two different methods such as ASTM C1018 and JSCE SF-4. The behaviour of steel fibre reinforced concrete indicated single peak response whereas polypropylene fibre reinforced concrete should double peak response. The deformations under two methods were compared.

A similar study had been conducted by Padmarajaiah and Ananth Ramaswamy (2004) on flexural strength of steel fibre reinforced high strength concrete in fully and partially pre stressed beam specimens. It is found that the toughness and ductility of pre stressed high strength concrete beams have increased with the increase in fibre content. The maximum increase in ductility was $18 \%, 45 \%$ and $68 \%$ and percentage increase in energy absorption $25 \%, 78 \%$ and $88 \%$ for fully pre stressed beams with full depth of steel fibre content of $0.5 \%, 1.0 \%$ and $1.5 \%$ volume fractions. Experimental investigation and Analytical modeling for flexural behaviour of reinforced fibrous concrete beams using synthetic fibres were performed by Suji et al (2006). Graded fibrillated polypropylene fibres were used in this study. A $1.8 \mathrm{~m}$ long rectangular reinforced concrete beam was cast with and without fibre at different volume fractions of $0.1 \%, 0.2 \%$ and $0.3 \%$. Moment carrying capacity of beams were arrived and compared with theoretical equations. Also it was concluded that the crack pattern remained the same for all beams, but the crack width and length were reduced for fibre reinforced concrete beams.

The ultimate strength of steel fibre reinforced self compacting concrete beams were tested by Ganesan et al (2006). A $1.2 \mathrm{~m}$ long reinforced concrete beams are prepared using self compacting concrete with steel fibres of three volume fractions of $0.25 \%, 0.5 \%$ and $0.75 \%$. It is found that strength and ductility of fibre reinforced self compacting concrete specimens have increased substantially over conventional concrete.

Load - Deflection performance of partially pre stressed concrete T-beams with steel fibres in partial and full depth was assessed by J. Thomas and A. Ramasamy (2006). Three mixes M35, M65 and M85 were used with steel fibres at a volume fraction of $1.5 \%$. Totally 6 numbers of $3.85 \mathrm{~m}$ long T-beams with simply supported span of $3.6 \mathrm{~m}$ pre stressed with 7 $\mathrm{mm}$ wires were casted and tested under four point bending. Analytical models were proposed for computation of load - deflection and moment curvature. The comparisons were made between the experimental and analytical results.

The same authors, Job Thomas and Ananth Ramasamy (2006) reported the details of finite element modeling and analysis of some shear critical pre stressed steel fibre reinforced concrete beams. A commercially available finite element software 'ANSYS' was used to analyse the beams. The concrete was model ed using 'SOLID 65' - an eight node brick model, which is capable of simulating the cracking crushing behaviour of brittle materials. The reinforcements were model ed using 'LINK 8' - a 3D spar element. The slip between reinforcement and the concrete has been modeled using 'COMBIN 39'- a non linear spring element. The ANSYS correctly predicted the diagonal tension and shear failure of pre stressed concrete beams observed in the experiment

Finite element analysis using ANSYS was done by Greeshma and Jaya (2007) to analyse a shear wall under seismic loading. Modeling of shear wall was 
done using SOLID 65 model and reinforcements were modeled using LINK 8 element. The analyses were carried out for the shear wall, subjected to both static and dynamic loading.

\section{FIBRE REINFORCED BEAM COLUMN JOINT UNDER CYCLIC LOADING}

An experimental investigation was conducted on the behaviour of beam-column joints with inclined reinforcing bars under seismic condition and reported by Tsonos et al (1992). By conducting experiments on twenty joints, it was concluded that, improvement in the ductile behaviour of exterior beam-column joints resulted in the presence of inclined reinforcing bars in their core region.

SIFCON is a special type of fibre reinforced concrete at high volume fraction (4 to 20\%) in which the formwork is filled to capacity with steel fibres and the resulting fibre network is then infiltrated by a cement based slurry. Ductile behaviour of SIFCON structural members was studied by Thirugnanamet al (2001). The investigation was carried out in two stages. Initially single span beams were tested to quantify the structural behaviour in the hinging zones of flexural members. In the second stage, multi bay, multi-storey RC frames were tested with SIFCON beam- column joints to study the structural behaviour under cyclic loading. The seismic parameters such as cumulative ductility, cumulative energy absorption, stiffness degradation and failure mode were obtained. It was concluded that ductility increased by $100 \%$ and energy absorption increased by $50 \%$, in hinging zones of structural joints because of SIFCON.

To clarify the effect of joint detailing on the seismic performance of lightly reinforced concrete frames, an experimental study was performed by Sathish kumar et al (2002). In that study lightly reinforced exterior beam-column joints were tested under cyclic loading to obtain the hysterises behaviour. It is concluded that axial load on columns not only increases the strength and ductility but also reduces the damage in the joint region.

An experimental investigation was carried out by Mustafa Gencoglu and Iihan Eren (2002) to study the effect of steel fibre reinforced concrete on the behaviour of the exterior beam-column joints subjected to reverse cyclic loading. To achieve the ductility in joints for earthquake resistant structures, closely spaced reinforcements are recommended by the code. To avoid the congestion of reinforcement, alternate solution was given in the literature. Steel fibres of aspect ratio 75 were added at a $1 \%$ volume fraction. Tests were conducted by applying reverse cyclic loading and mode of failure and energy dissipation capacity was observed. It was concluded that steel fibres can be used as an alternative for the increase in confining reinforcement so as to minimise the congestion of reinforcement at beam-column joint and hence reduce the problem of consolidation of concrete.

Intrinsic response control of moment resisting frames using advance composite materials and structural elements was tested by Gregor Fischer and Victor C. $\mathrm{Li}$ (2003). In this research work, the load-deformation response of a composite frame system, under reverse cyclic loading condition was investigated. From this work it was concluded that engineered cementitious composites and fibre reinforced polymer reinforcements can be used as alternative approach for earthquake resistant structures, with improved performance in terms of dynamic response, residual displacement, damage tolerance and rehabilitation requirements.

Seismic performance of confined high strength concrete square columns with carbon fibre reinforced polymers was experimented by Hosseini et al (2005). To evaluate the performance of high strength, reinforced concrete columns confined with carbon fibre reinforced polymers; six square concrete columns were tested under constant axial load and cyclic lateral load. The energy damage indicator and ductility parameters of strengthened columns were improved. Both system and section ductility and energy dissipation improved considerably in strengthened joints.

As seismic design of structures moves towards performance based design, there is a need for a few structural members and systems that possess enhanced deformation capacity and damage tolerance, while requiring simple reinforcements. One option for achieving this goal was given and experimented by Gustavo J. Parra-Montesinos et al (2005). Using High-performance fibre-reinforced cement composites, high damage tolerant beam-column joints were achieved. It is concluded that beam-column joints constructed with an HPFRCC material containing a $1.5 \%$ volume fraction of ultra-high molecular weight polyethylene fibres exhibited 
excellent strength, deformation capacity and damage tolerance. It is also reported that use of HPFRCC materials in beam plastic regions allowed an increase in transverse reinforcement spacing to half the effective beam depth.

Asha et al (2006) carried out an experimental investigation on cyclic response of reinforced concrete exterior beam - column joints. Two types of reinforcement were considered namely circular hoop and conventional reinforcement. Load-displacement hysteresis loops were drawn and hence cumulative energy absorption and ductility were ascertained.

A similar study was carried out by Valeria Corinadesi and Giacomo Moriconi (2006) on behaviour of beamcolumn joints made of sustainable concrete. In this study, two different types of aggregares namely natural aggregates and recycled aggregates were used. In order to ascertain the real scale behaviour, several beam-column joints were cast and tested under low cycle loading. There are two options in seismic design. One is design of structures with full strength so it will respond elastically while ensuring adequate ductility and energy absorption. Second one permits the structure to be designed for considerably lower forces than those required for first one. Here also ductility and energy dissipation capability were ascertained based on the load- displacement hysteristic loops.

Strength and ductility of partially confined bridge column under seismic loading were studied by Prapakaran and Sundararajan (2007). The main objective of the study was to investigate the influence of partial confinement at plastic hinge region on the structural characteristics of circular bridge column. Based on the lateral load - tip displacement hysteristic loops, cumulative energy absorption were calculated and compared.

\section{REVIEWS ON WASTE FIBROUS MATERIALS}

India owns a huge amount of waste materials in the form of organic and inorganic matter. Nowadays, inorganic waste materials such as plastic, nylon, rubber are produced in massive volumes because of an increase in the use of inorganic materials for various purposes such as automobile parts, household goods, industrial wastes etc., One of the leading problems of generating these inorganic waste materials is disposal without environmental pollution. Some common methods of solid waste disposal are land filling and incineration. But these methods are uneconomic. So, attempts to reuse the waste materials for construction purposes have been made by many researchers in many forms. Similarly organic natural fibres are abundantly available in many parts of the world. For different reasons, developing countries recognise the importance of the use of ecologically friendly and cost effective Materials in urban and rural buildings. This section will elaborate the studies carried out the researchers on inorganic fibrous materials.

\section{REVIEWS ON INORGANIC FIBERS}

A study was conducted to investigate the feasibility of recycling commingled plastics Fibre in Concrete by Kenneth W. Stier and Gary D. Weede (1999). Fresh concrete properties such as slump and air content along with mechanical strength properties such as compressive and flexural strength properties were studied. It was concluded that concrete containing recycled plastics fibre showed promising results in mechanical strength results and inconsistent results in durability studies.

Sekar (2004) studied on fibre reinforced concrete from industrial waste fibers and reported that waste fibers such as lathe waste and wire winding waste significantly improved the compressive, split tensile and flexural strength values of concrete. It was also stated that wire drawing industry waste decreased the strength values.

Some studies on properties of concretes containing reengineered plastic shred fibre were studied by Anbuvelan et al (2007). Reengineered plastic shred fibres are made by re- processing the plastic waste and then rolling it into plastic sheets which were subsequently shredded into fibres of required dimensions. Compressive, split tensile, flexural, abrasion, impact strength and plastic shrinkage studies were studied by the authors. It was concluded that the engineering properties improved by the addition of plastic shred fibres.

\section{REVIEW ON NATURAL FIBRES}

Natural fibres are prospective reinforcing materials and their use until now has been more traditional than technical. They have long served many useful purposes but the application of materials technology for the utilization of natural fibres as the reinforcement in concrete has only taken place in comparatively recent years. The distinctive properties of natural fibre reinforced concretes are improved 
tensile and bending strength, greater ductility, greater resistance to cracking and hence improved impact strength and toughness. Besides its ability to sustain loads, natural fibre reinforced concrete is also required to be durable. Durability relates to its resistance to deterioration resulting from external causes as well as internal causes (Aziz et al1984).

Mechanical characterization and impact behaviour of concrete reinforced with natural fibres were studied by Al-Oraimi and Seibi (1995). Here an experimental study was conducted using glass and palm tree fibres on high strength concrete. Mechanical strength properties such as compressive, split tensile, flexural strengths and post cracking toughness were studied. It was concluded that natural fibres are comparable with glass fibres. A finite element analysis was also done using ANSYS software. Both the analytical and experimental results were compared and acceptable. Ramakrishna et al (2002) compared the theoretical and experimental investigations on the compressive strength and elastic modulus of coir and sisal fibre reinforced concretes for various volume fractions. It was observed that both the experimental and analytical values of elastic modulus had shown $15 \%$ discrepancy, which can be regarded as comparatively small.

Rheological properties of coir fibre reinforced cement mortar were carried out by Ramakrishna and Sundararajan (2002). Flow value, cohesion and angle of internal friction were determined for three diffrenet mix ratios and four different aspect ratios and fibre contents. Based on the rheological properties of fresh mortar, it was recommended to use shorter fibres with low fibre- content for achieving workability and higher fibre content for better cohesiveness in wet state.

Sugarcane bagasse fibre reinforced cement composites were studied by.Bilba et al (2003). Various bagasse fibre-cement composites were prepared and influence various parameters on the setting of the composite materials were studied. Botanical components, thermal and chemical treatment of bagasse fibres were also studied.

The natural fibre composites may undergo a reduction in strength and toughness as a result of weakening of fibres by the combination of alkali attack and mineralisation through the migration of hydrogen products to lumens and spaces. Romildo D. Toledo
Filho et al (2003) reported their study on development of vegetable fibre-mortar composites of improved durability. So, several approaches were proposed by the authors to improve the durability of vegetable fibre-cement composites. These include carbonation of the matrix in a CO2-rich environment; the immersion of fibres in slurried silica fume prior to incorporation in Ordinary Portland Cement matrix; partial replacement of Ordinary Portland Cement by undensified silica fume or blast furnace slag. The performance of modified vegetable fibre-mortar composites was analysed in terms of effects of aging in water, exposure to cycles of wetting and drying and open air weathering on the microstructures and flexural behaviour.

It was suggested that immersion of natural fibres in a silica fume slurry before the addition to the cement based composites was found to be an effective means of reducing embrittlement of the composite in the environment. Also early cure composites in a $\mathrm{CO} 2$ rich environment and the partial replacement of OPC by undensified silica fume were the efficient approaches in obtaining natural fibres with improved durability.

Robert S. P. Coutts (2005) reviewed critically the Australian research into natural fibre cement composites. It was mentioned that over the last three decades considerable research has been committed to finding an alternative fibre to replace asbestos and glass fibres.

Agopyan et al (2005) reported the developments on vegetable fibre-cement based materials in Brazil. Taking into account the mechanical properties, with an adequate mix design, it is possible to develop a material with suitable properties for building purposes. To overcome the drawback, it was suggested that durability of natural fibres can be improved by making alternative binders with controlled free lime using ground granulated blast furnace slag.

Romildo D. Toledo Filho et al (2005) made some experiments on free, restrained and drying shrinkage of cement mortar composites reinforced with vegetable fibres. The free and restrained shrinkage were studied by subjecting the specimens to wind speed of $0.4-0.5 \mathrm{~m} / \mathrm{s}$ at 40 o $\mathrm{C}$ temperature for 280 min. The drying shrinkage tests were carried out at room temperature with about $41 \%$ relative humidity 
for 320 days. It was concluded that free plastic shrinkage is significantly reduced by the inclusion of $0.2 \%$ volume fraction of $25 \mathrm{~mm}$ short sisal fibres in cement mortar. Also, it was stated that the presence of sisal and coconut fibres promote an effective selfhealing of plastic cracking after 40 days at $100 \% \mathrm{RH}$.

The capability to absorb energy, called toughness is important in actual service conditions. For that purpose, an experimental investigation was carried out by Ramakrishna and Sundararajan (2005) on impact strength of a few natural fibre reinforced cement mortar slabs. Four types of natural fibres such as coir, sisal, jute and hibiscus cannebinus with four different fibre contents such as $0.5 \%, 1.0 \%, 1.5 \%$ and $2.0 \%$ by weight of cement were used. The tests were carried out using repeated projectile test apparatus and the performance of specimens was ascertained based on the parameters namely impact resistance, residual impact ratio, crack resistance ratio and the condition of fibre at ultimate. From this elaborative test results, it was concluded that coir fibres absorb more energy ie., $253.5 \mathrm{~J}$ at $2 \%$ fibre content and fibre length of 40 $\mathrm{mm}$.

Some studies have also been conducted by Ramakrishna and Sundararajan (2005) on the durability of natural fibres and the effect of corroded fibres on the strength of mortar. Coir fibres were found to retain higher percentages of their initial strength than all other fibres after the specified exposure in the various mediums.

Mechanical properties of date palm fibres and concrete reinforced with date palm fibres were tested and reported by Kriker et al (2005) in two different climates. In addition to the above properties, continuity index, microstructure and toughness were also studied. The volume fraction and length of fibres chosen were $2-3 \%$ and $15-60 \mathrm{~mm}$ respectively. It was concluded that male date palm fibre got more tensile strength. Also it was stated that observing micro-structure of the fibre-matrix interface cured in hot - dry and water environments. Based on the results and observations of that work, it was suggested that future research should be developed on the treatment of male date palm surface fibre concrete in order to improve their mechanical properties using local industrial waste, especially in a hot-dry climate.
Microstructure and mechanical poperties of waste fibre-cement composites were studied by Savastano Jr et al (2005). Both secondary and back-scattered electron imaging and energy dispersive X-ray spectrography were used for compositional analysis. It was concluded that sisal waste fibres presented satisfactory results in bonding in matrices. BSE images and EDS analyses confirmed that fibre-matrix transition zone can be improved by using a production process based on vacuum dewatering and pressure.

\section{INGREDIENTS GLASS FIBRE MODIFIED HPC}

This experimental program is designed to investigate the integration of Glass fibre with high performance concrete of a design mi of M60 grade of concrete. the influence of the cementations materials, percentage of fibres and the mixing procedures on the mechanical properties of fibre based concrete together with the workability was studies by preparing several concrete mixs.

The test procedures, details and equipments used to assess concrete properties are illustrated in the following sections

\section{MATERIALS}

\section{Cement}

Fine Aggregate

Coarse Aggregate

Chemical Admixture

- Super Plasticizer

$>$ Mineral Admixture

- Silica Fume

- GGBS (Ground Granulated Blast Furnace Fume)

Glass Fibre

$>$ Water

\section{Cement}

In this present investigation OPC 53 Grade with a brand name Ultra Tech (Birla super) used. Tests are conducted in accordance with Indian standard confirming to is-12269:1987. The physical characteristic of the tested cement has been shown in table 4.1 
International Journal of Trend in Scientific Research and Development (IJTSRD) ISSN: 2456-6470

\begin{tabular}{|c|c|c|c|}
\hline \multicolumn{4}{|c|}{$\begin{array}{l}\text { PHYSICAL PROPERTIES OF CEMIENT } \\
\text { Reference IS:12267-1987 ( Reaffirmed 2008) }\end{array}$} \\
\hline S. No & Test Conducted & Results & Requirements as per IS \\
\hline 1 & Specific Gravity & 3.15 & \\
\hline 2 & Fineness of cement & $1.3 \%$ & \\
\hline 3 & Standard Consistency & $30 \%$ & Not specified \\
\hline 4 & Soundness (Le-chatelier's) & $0.5 \mathrm{~mm}$ & Shall not be more than $10 \mathrm{~mm}$ \\
\hline \multirow[t]{7}{*}{5} & Setting time(in min) & & \\
\hline & Initial Setting Time & 60 & Shall not be less than 30 minutes \\
\hline & Final Setting Time & 210 & Shall not be less than 600 minutes \\
\hline & $\begin{array}{l}\text { Compressive strength (Mpa) } \\
(70.6 * 70.6 * 70.6 \mathrm{~mm} \text { cubes })\end{array}$ & & \\
\hline & 3 days & 39.0 & Shall not less than $27.0 \mathrm{Mpa}$ \\
\hline & 7 days & 44.2 & Shall not less than $37.0 \mathrm{Mpa}$ \\
\hline & 28 days & & $\begin{array}{l}\text { Shall not less than } 53.0 \\
\text { Mpa }\end{array}$ \\
\hline
\end{tabular}

Table: 3.1 Physical Characteristics of Cement

FINE AGGREGATE:-

Both the natural sand and crushed stone dust can be used as fine aggregate, should consist of rounded particles to reduce water demand. A fineness modulus of 2.4 to 3 and zone $\square$ type of sand is recommended in IS: 383(1970) is found to be suitable for HPC production.

\begin{tabular}{|ll|l|}
\hline 1. & Fineness modulus & 2.70 \\
\hline 2. & Bulk Density $\left(\mathrm{Kg} / \mathrm{m}^{3}\right)$ & \\
& $>$ Dense & 1600 \\
& $>$ Loose & 1422 \\
\hline 3. Specific gravity & 2.67 \\
\hline 4. Void Ratio & $36 \%$ \\
\hline 5. Zone & $\mathrm{II}$ \\
\hline
\end{tabular}

Table 3.2:-Properties of fine aggregate

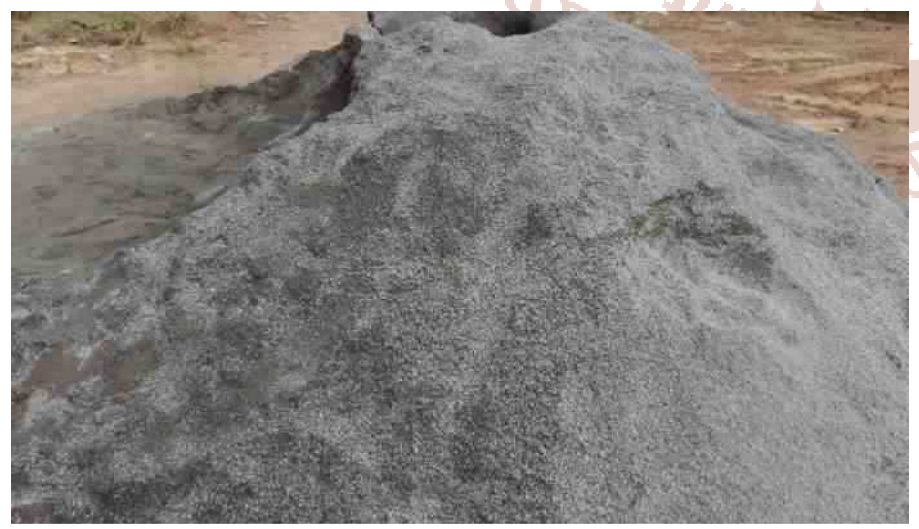

Fig 3.2 Fine aggregate

\section{COARSE AGGREGATE:-}

The CA is the strongest and least porous component of concrete. Iy is also a chemically stable material. As in concrete occupies 35 to $75 \%$ of concrete volume of the HPC. They often control the behaviour of concrete in workability, durability, strength and economy, their properties play significant role in determining the properties of hardened cement.

It may be proper to categories the properties into two groups: exterior feature (MSA, particle shape, texture) and interior quality (strength density, porosity, hardness, elastic modulus, chemical and mineral composition etc.)

Smaller size aggregate produce higher concrete strength, particle shape and texture affect the workability of fresh concrete and strength of hardened concrete.

The strength properties of $\mathrm{CA}$, such as aggregate abrasion value, aggregate impact value, modulus of elasticity compressive strength and aggregate crushing value etc. would determine limit for HPC.

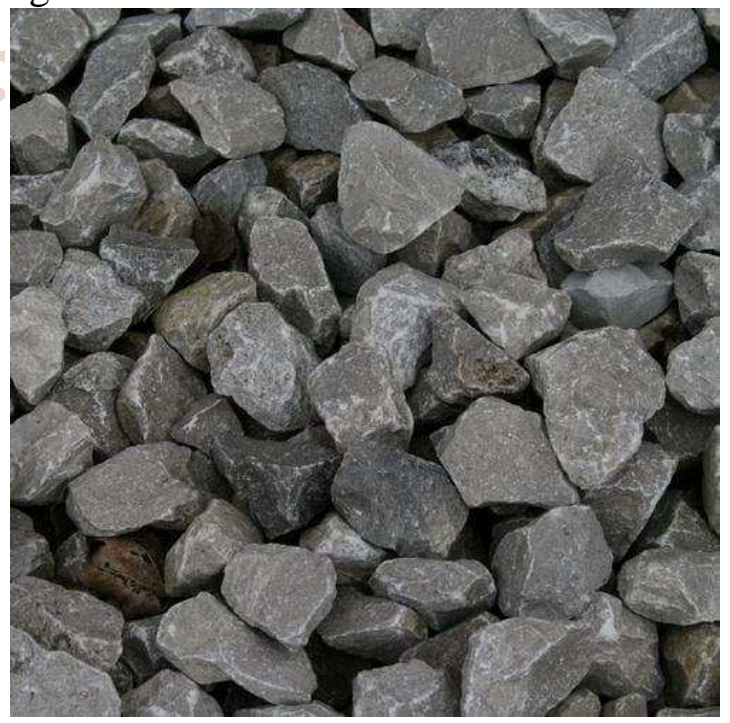

Fig 3.3 Coarse aggregate 
Mehta and Aitcin recommended a max size of 10$12 \mathrm{~mm}$.

Since the aggregate - cement paste interface is very strong in HPC; the strength of aggregate can be a limiting factor. But with the most of rock reducing MSA to $10-15 \mathrm{~mm}$ will eliminate most of the defects within the aggregate. The presence of CA reduces the drying shrinkage and other dimensional changes occurring on account of movement of moisture. CA contributes to impermeability of concrete.

As regard the shape of the aggregate, cubical, crushed, equi-dimensionl aggregates are suitable. From petro logical stand point, limestone, dolomite limestone and granite are equally good.

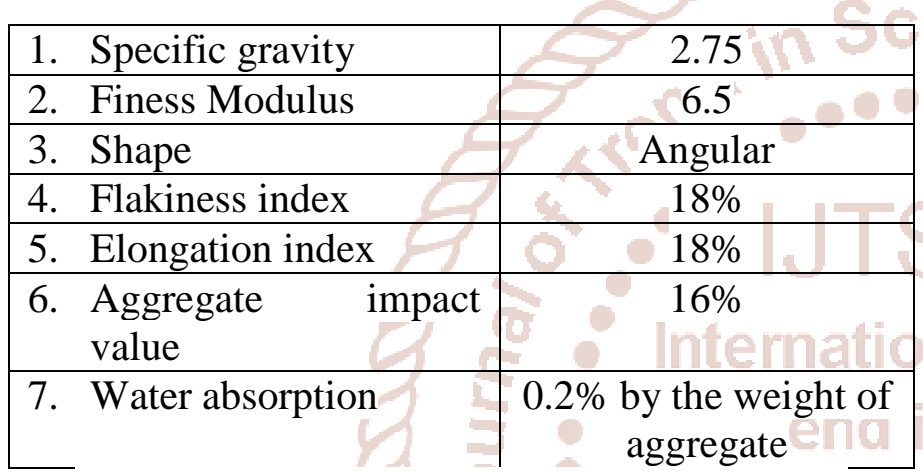

Table-3.3 Properties of coarse aggregate used:

\section{WATER:-}

Water is the most important and least expensive ingredient of concrete as it actively participates in the chemical reaction with cement. A part of water get utilised in hydration in cement, to form binding matrix and remaining water serves as lubricant between FA and CA and make the concrete workable.

Generally the cement requires about $3 / 10$ of its weight for hydration. Hence mini water cement ratio required is 0.35 . But additional water is required to lubricate the mix which makes the concrete workable. The water demand is kept min with the use of super plasticiser which is very much essential for HPC, thus the water- binder ratio of 0.25 to 0.34 is ideal for HPC.

Too much water reduces the strength of concrete. If too much water is added to concrete, the excess water along with cement comes to the surface by capillary action and this cement water mixture forms a thin layer of chalky material known as "laitance". This laitance prevents bond formations and forms s plane of weakness in concrete.

\section{Chemical admixture:-}

Chemical admixtures are essential ingredients of concrete as it actively participate in the chemical reactions with cement and increase the efficiency of cement paste by improving the workability of mix and there by considerable decrease of water requirement thus with water cement ratio as low as 0.26 the concrete nix can be cast.

The important types of admixture used in HPC.

$>$ Plasticiser and superplasticiser

$>$ Retarders

$>$ Air- retainers

Plasticiser and superplasticiser being surfactant in nature helps to disperse the cement particles in mixand thus the mobility/fluidity of concrete mix is enhanced.

Retarders reduce the initial rate of hydration of cement so that the fresh cement concrete retains its workability for a longer time.

Air-entraining agents artificially introduce air bubbles which increase the workability of the mix by their ball bearing action and enhance resistance to deterioration due to freezing and thawing action.

\section{Superplasticiser:-}

It is essentially impossible to make high performance concrete at adequate workability without the use of superplasticiser.

The high concentration of cement particles in the mixing water requires high superplasticiser dosage to complete deflocculates and disperse the suspensions of cement particles, superplasticiser are polymers that can interact physically and chemically with cement particles.

Different superplasticiser will behave quite differently with different cements. This is due in part to the variability in the minor component of cement and in part to the acceptance standards for plasticiser themselves are not very clearly written. Thus, some cement will simply be found to be incompatible to certain superplasticiser.

\section{Optimization of dosage of superplasticisers:-}

The max economy, while using superplasticised concrete can be obtained when the dosage of super plasticiser is optimized. There is no exact method of determining the required the superplasticiser dosage 
therefore it has to be determined by trial and error method.

One of the key points in the design of a superplasticiser concrete or more specifically a HPC, is the determination of optimum dosage of superplasticiser. One approach for those purposes is that based on the Marsh cone test on pastes (or) mortars, which has been used to determine the saturation dosage of superplasticiser, as well as the compatibility between admixture and cement (Aitcinet. Al. 1994; Toralles- carbonerite. Al. 1996; Gettuet. Al. 1997).

The saturation point varies from cement to another, when using the same superplasticiser, and from one superplasticiser dosage at saturation point depends on the $\mathrm{W} / \mathrm{c}$ ratio of the mix.

The fitness of cement, the total amount of $\mathrm{C} \square \mathrm{A}$, The sulphate content and the rate of dissolution of sulphate and the mix design there in are one superplasticiser dosage. For this purpose, experiments were conducted to find out the optimum dosage of superplasticiser for the required workability. The study deals with an approach to optimize the dosage superplasticiser for max reduction in water- cement ratio requirements for the required workability as same has been discussed detail in present investigation.

\section{SILICA FUME / MICRO SILICA:}

Concrete having compressive strength up to 50Mpa can be made without silica fume, beyond this strength use of silica fume becomes essential; it is generally a component of HPC mix.

Silica fume is a by-product of the manufacture of silicon or various silicon alloys, produced in submerged electric arc furnaces. Micro silica is available in various forms such as undensified, dansified, palletised or slurry form.

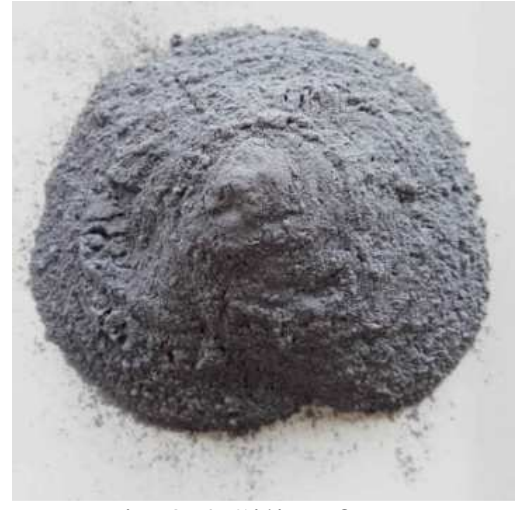

Fig 3.4 Silica fume
UNDENSIFIED:

Its density is typically $200-350 \mathrm{~kg} / \mathrm{m} 3$. It is collected from a filter as a very fine light powder which is used in formulator production bagge concrete, mortar and grouts.

\section{DENSIFIED:}

It has a density of $500-700 \mathrm{~kg} / \mathrm{m} 3$. It is basically processed to increase the bulk density by loosely agglomerating the fine particles. Its uses include some formulated products pre-cast operations and ready mix concretes.

\section{PELLETESID:}

Its density is around $1000 \mathrm{~kg} / \mathrm{m} 3$. This form has been treated with a small amount of cement and water to give the solid agglomerate it is normally used only for intergrainding with cement and cannot disperses beyond the actual grainding.

\section{SLURRY:}

It is an aqueous suspension of undensified micro silica in water usually at $50 \%$ weight for weight. The material has aspecific gravity of arund 1.4 and as a liquid is easier to handle than the powders.

\begin{tabular}{|ll|c|}
\hline 1. & Specific gravity & 2.26 \\
\hline 2. & Bulk loose density & $600-700$ \\
\hline 3. & colour & Grey \\
\hline
\end{tabular}

TABLE 3.4: PHYSICAL PROPERTIES OF SILICA FUME

\begin{tabular}{|c|c|}
\hline CONSTITUENTS & PERCENTAGE \% \\
\hline SIO2 & Min 85 \\
\hline Carbon & Max 2.5 \\
\hline Loss of ignition & Max 4 \\
\hline Water moisture & Max 1 \\
\hline
\end{tabular}

\section{TABLE 3.5 CHEMICAL COMPOSITION OF SILICA FUME}

\section{GROUND GRANULATED BLAST FURNACE SLAG [GGBS]:}

Blast furnace slag is a by-product of iron manufacture. When quenched rapidly with water to a glassy state and fines ground, it develops the latest hydraulic city.

The proportion of GGBS to be used in concrete depend upo the job requirements. The usual proportions vary from 25 to $50 \%$ by weight of cement. 
On a cement replacement resistance, then the slag content is at least $50 \%$ of the total constitution material.

\begin{tabular}{|c|c|}
\hline Parameter & Specification's \\
\hline 1. Colour & $\begin{array}{c}\text { Light grey, concrete } \\
\text { specimen exhibits deep blue } \\
\text { - green colour when tested. }\end{array}$ \\
\hline $\begin{array}{l}\text { 2. Specific } \\
\text { gravity }\end{array}$ & $2.85-2.95$ \\
\hline $\begin{array}{l}\text { 3. } \begin{array}{l}\text { specific } \\
\text { surface }\end{array}\end{array}$ & $450 \mathrm{M}^{2} / \mathrm{Kg}$ \\
\hline 4. structure & $\begin{array}{l}\text { Glassy state and finely } \\
\text { ground }\end{array}$ \\
\hline $\begin{array}{l}\text { 5. magnesia } \\
\text { content }\end{array}$ & $\operatorname{Max} 14 \%$ \\
\hline $\begin{array}{ll}\text { 6. } & \text { loss } \\
\text { Ignition }\end{array}$ of & $\operatorname{Max} 3 \%$ \\
\hline
\end{tabular}

Table 3.6 physical properties of GGBS

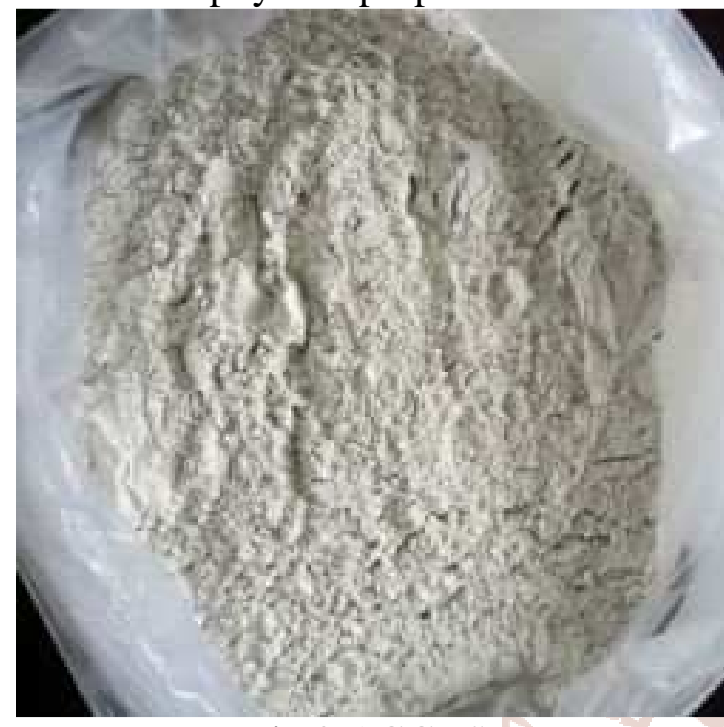

Fig 3.5 GGBS

\section{Properties of Glass Fibre}

\begin{tabular}{|ll|c|}
\hline & Type of glass fibre & Fiber AR Glass \\
\hline 1. & Specific Gravity & 2.68 \\
\hline 2. & Diameter & $.5-.7 \mathrm{~mm}$ \\
\hline 3. & Length & $12 \mathrm{~mm}$ \\
\hline 4. & Number of Fibres & $235 \mathrm{million} / \mathrm{Kg}$ \\
\hline 5. & Tensile Strength (Mpa) & $1700 \mathrm{~N} / \mathrm{mm}^{2}$ \\
\hline 6. & Elastic Modulus & $72 \mathrm{Gpa}$ \\
\hline
\end{tabular}

Table 3.7 Properties of Glass Fiber

\section{CASTING AND CURING PROCEDURE:}

For casting a well prepared concrete mixed in to the mould. Firstly, the surface to be in contact with the concrete was thoroughly oiled. The cubes cylinders and the beams are filled with three layers of concrete and each layer was compacted using needle vibrator.

For curing, wet gunny bags were used in cabe of Beam specimens. Cubes, cylinders prisms were submerged into water in a tank.

Steel moulds of two channels a section of reinforcement was then placed in required clear cover on the bottom.

\section{TESTING}

\section{Compressive strength of concrete:}

Out of many test applied to the concrete, this is the utmost important which gives an idea about all the characteristics of concrete. By this single test one judge that whether Concreting has been done properly or not.

Compressive strength of concrete depends on many factors such as water-cement ratio, cement strength, quality of concrete material, and quality control during production of concrete etc.

Test for compressive strength is carried out either on cube or cylinder. Various standard codes recommend concrete cylinder or concrete cube as the standard specimen for the test. American Society for Testing Materials ASTM C39/C39M provides Standard Test Method for Compressive Strength of Cylindrical Concrete Specimens.

\section{Procedure: Compressive Strength Test of Concrete Cubes}

For cube test two types of specimens either cubes of $15 \mathrm{~cm} X 15 \mathrm{~cm} X 15 \mathrm{~cm}$ depending upon the size of aggregate are used. For most of the works cubical moulds of size $15 \mathrm{~cm} \times 15 \mathrm{~cm}$ x $15 \mathrm{~cm}$ are commonly used.

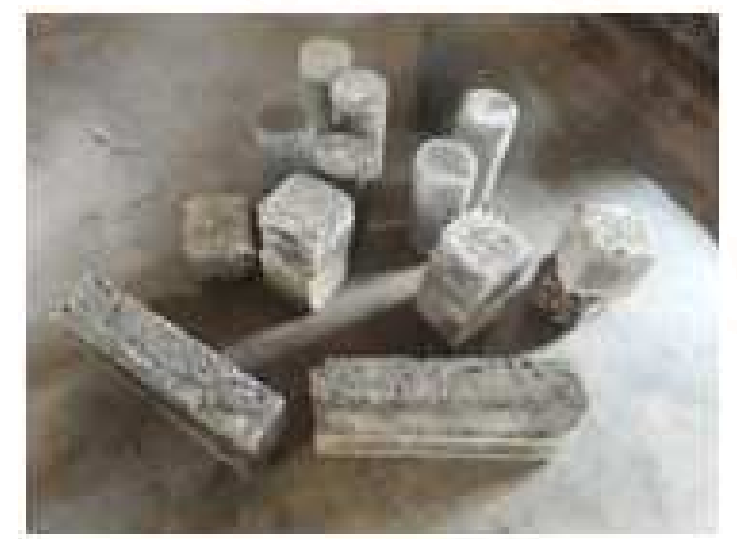

Fig 3.6 Specimen Cube 
This concrete is poured in the mould and tempered properly so as not to have any voids. After 24 hours these moulds are removed and test specimens are put in water for curing. The top surface of these specimens should be made even and smooth. This is done by putting cement paste and spreading smoothly on whole area of specimen.

These specimens are tested by compression testing machine after 3 days, 7 days and 28 days curing. Load should be applied gradually at the rate of $140 \mathrm{~kg} / \mathrm{cm} 2$ per minute till the Specimens fails. Load at the failure divided by area of specimen gives the compressive strength of concrete.

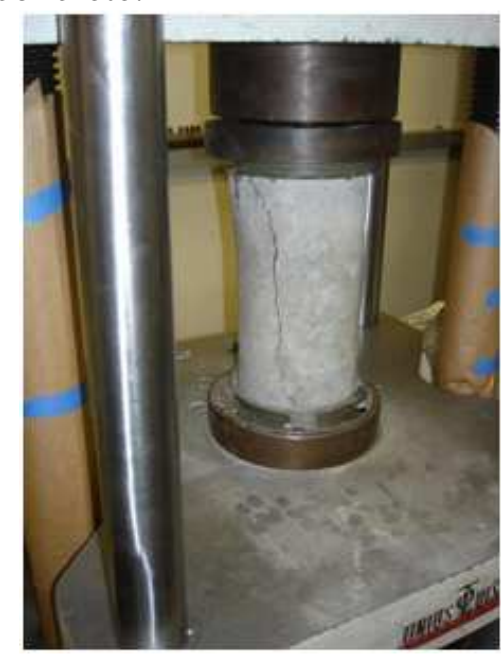

Fig 3.7 Compressive Test and to determine the development length of the reinforcement.

$$
\mathrm{T}=2 \mathrm{P} /(\mathrm{ld})
$$

Where, $\mathrm{T}=$ Splitting tensile strength (to be reported in $0.05 \mathrm{MPa}$ multiples)

$\mathrm{P}=$ Applied load, L=length of the specimen $(\mathrm{mm})$, $\mathrm{D}=$ Diameter of the specimen $(\mathrm{mm})$

\section{Apparatus:}

\section{$>$ Testing Machine}

$>$ Supplementary Bearing Bar Or Plates (If the diameter or the largest dimension of the upper bearing face or the lower bearing block is less than the length of the cylinder to be tested, a supplementary bearing bar or plate of machined steel shall be used. The bar or plate shall be manner that the load will be applied over the specimen.)

$>$ Bearing Strips (Two bearing strips of nominal $1 / 8$ in [3.2 $\mathrm{mm}$ ] thick plywood, free of imperfections, approximately $1 \mathrm{in}$. [25 mm] wide, and of a length equal to, or slightly longer than, that of the specimen shall be provided for each specimen. The bearing strips shall be placed between the specimen and both the upper and lower bearing blocks of the testing machine or between the specimen and supplemental bars or plates, when used.

\section{Tensile strength}

The tensile strength of concrete is one of the basic and important properties. Splitting tensile strength test on concrete cylinder is a method to determine the tensile strength of concrete. The concrete is very weak in tension due to its brittle nature and is not expected to resist the direct tension. The concrete develops cracks when subjected to tensile forces. Thus, it is necessary to determine the tensile strength of concrete to determine the load at which the concrete members may crack.

This test method is used for the determination of splitting tensile strength of cylindrical concrete specimen. Splitting tensile strength is helpful for the following purposes;

Splitting tensile strength is generally greater than the direct tensile strength and lower than the flexural strength (modulus of rupture).

$>$ Splitting tensile strength is used in the design of structural light weight concrete members to evaluate the shear resistance provided by concrete

\section{Size of the Specimen:-}

The specimen is a cylinder of $150 \mathrm{~mm}$ diameter and $300 \mathrm{~mm}$ height. Determine the diameter to the nearest $0.25 \mathrm{~mm}$ by averaging the three diameters. Determine the length to the nearest $2 \mathrm{~mm}$ by averaging at least two lengths.

\section{Size of Bearing Strips:-}

According to ASTM specifications, the bearing strips should be $3.2 \mathrm{~mm}$ thick and $25 \mathrm{~mm}$ wide. There is no restriction on their length.

The specimen is a cylinder of $150 \mathrm{~mm}$ diameter and $300 \mathrm{~mm}$ height. Determine the diameter to the nearest $0.25 \mathrm{~mm}$ by averaging the three diameters. Determine the length to the nearest $2 \mathrm{~mm}$ by averaging at least two lengths.

\section{Rate of Loading:-}

The rate of loading should be such that a stress of 0.7 $-1.4 \mathrm{MPa} / \mathrm{min}$ is produced. 


\section{Size of Bearing Strips:-}

According to ASTM specifications, the bearing strips should be $3.2 \mathrm{~mm}$ thick and $25 \mathrm{~mm}$ wide. There is no restriction on their length

\section{Procedure:}

This test method consists of applying a diametrical force along the length of a cylindrical concrete at a rate that is within a prescribed range until failure. This loading induces tensile stresses on the plane containing the applied load and relatively high compressive stresses in the area immediately around the applied load. Although we are applying a compressive load but due to Poisson's effect, tension is produced and the specimen fails in tension. Tensile failure occurs rather than compressive failure because the areas of load application are in a state of triaxial compression, thereby allowing them to withstand much higher compressive stresses than would be indicated by a uniaxial compressive strength test result. Thin, plywood bearing strips are used to distribute the load applied along the length of the cylinder. The maximum load sustained by the specimen is divided by appropriate geometrical factors to obtain the splitting tensile strength.

\section{Calculations:-}

Calculate the splitting tensile strength of the specimen as $\quad \mathrm{T}=2 \mathrm{P} /(\mathrm{Ld})$

Where: $\mathrm{T}=$ splitting tensile strength, $(\mathrm{psi}$ or MPa)

$\mathrm{P}=$ maximum applied load indicated by the testing machine, $(\mathrm{N}) \mathrm{d}=$ diameter, (in. or $\mathrm{mm}$ ), $\mathrm{L}=$ length, (cm or $\mathrm{mm}$ )

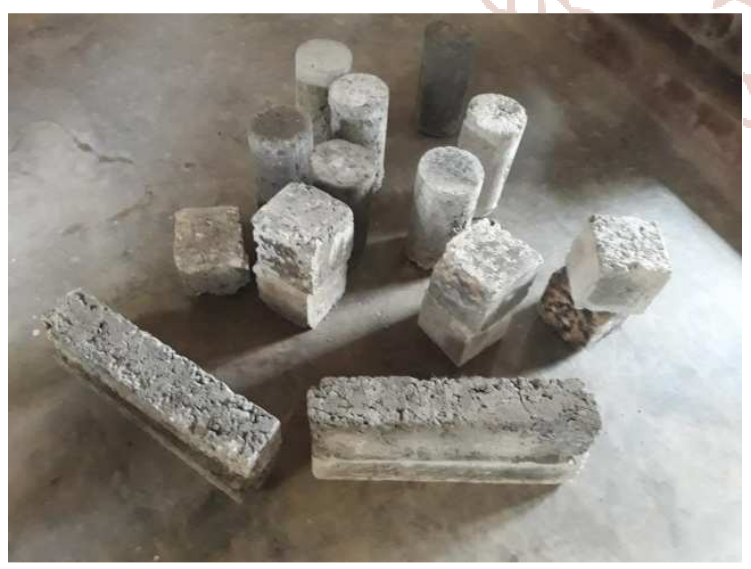

Fig.3.9 Tensile test
Flexure strength:-

Flexural strength is one measure of the tensile strength of concrete. It is a measure of an unreinforced concrete beam or slab to resist failure in bending. It is measured by loading $6 \times 6$ inch $(100 \mathrm{x}$ $100-\mathrm{mm}$ ) concrete beams with a span length at least three times the depth. The flexural strength is expressed as Modulus of Rupture (MR) in psi (MPa) and is determined by standard test methods ASTM C 78 (third-point loading) or ASTM C 293 (center-point loading).

Flexural Strength of Concrete Flexural MR is about 10 to $20 \%$ of compressive strength depending on the type, size and volume of coarse aggregate used. However, the best correlation for specific materials is obtained by laboratory tests for given materials and mix design. The MR determined by third-point loading is lower than the MR determined by centerpoint loading, sometimes by as much as $15 \%$. The test for flexural strength of concrete beams under third point loading utilizes a beam testing machine which permits the load to be applied normal to the loaded surface of the beam. The specimen is tested on its side with respect to its molded position. The beam is centered on the bearing supports. The dial indicator of the proving ring is placed at the zero reading. The load is applied at a uniform rate and in a way to avoid shock. The load required to cause specimen failure is obtained from the dial indicator's final reading and the proving ring calibration curve.

\section{Flexural test machine:-}

The bed of the testing machine shall be provided with two steel rollers, $38 \mathrm{~mm}$ in diameter, on which the specimen is to be supported, and these rollers shall be so mounted that the distance from centre to centre is $60 \mathrm{~cm}$ for $15.0 \mathrm{~cm}$ specimens or $40 \mathrm{~cm}$ for $10.0 \mathrm{~cm}$ specimens. The load shall be applied through two similar rollers mounted at the third points of the supporting span that is, spaced at 20 or $13.3 \mathrm{~cm}$ centre to centre. The load shall be divided equally between the two loading rollers, and all rollers shall be mounted in such a manner that the load is applied axially and without subjecting the specimen to any torsional stresses or restraints. 


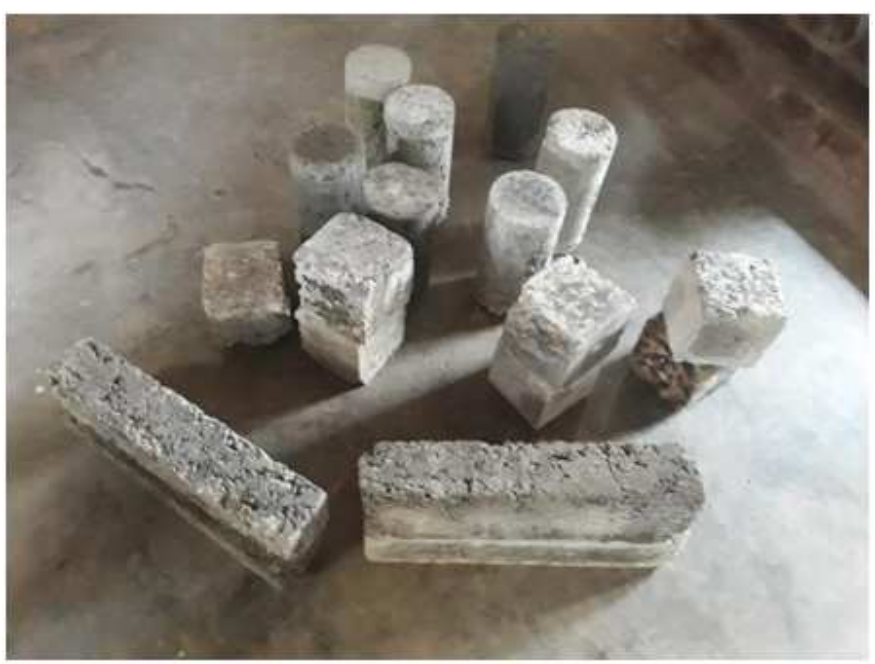

Fig 3.10 Flexural Strength Test Arrangement

\section{PROCEDURE}

1. Prepare the test specimen by filling the concrete into the mould in 3 layers of approximately equal thickness. Tamp each layer 35 times using the tamping bar as specified above. Tamping should be distributed uniformly over the entire crossection of the beam mould and throughout the depth of each layer.

2. Clean the bearing surfaces of the supporting and loading rollers, and remove any loose sand or other material from the surfaces of the specimen where they are to make contact with the rollers.

3. Circular rollers manufactured out of steel having cross section with diameter $38 \mathrm{~mm}$ will be used for providing support and loading points to the specimens. The length of the rollers shall be at least $10 \mathrm{~mm}$ more than the width of the test specimen. A total of four rollers shall be used, three out of which shall be capable of rotating along their own axes. The distance between the outer rollers (i.e. span) shall be $3 \mathrm{~d}$ and the distance between the inner rollers shall be $d$. The inner rollers shall be equally spaced between the outer rollers, such that the entire system is systematic.

4. The specimen stored in water shall be tested immediately on removal from water; whilst they are still wet. The test specimen shall be placed in the machine correctly centered with the longitudinal axis of the specimen at right angles to the rollers. For moulded specimens, the mould filling direction shall be normal to the direction of loading.

5. The load shall be applied at a rate of loading of $400 \mathrm{~kg} / \mathrm{min}$ for the $15.0 \mathrm{~cm}$ specimens and at a rate of $180 \mathrm{~kg} / \mathrm{min}$ for the $10.0 \mathrm{~cm}$ specimens.

\section{CALCULATION}

The Flexural Strength or modulus of rupture $(\mathrm{fb})$ is given by

$\mathrm{fb}=\mathrm{pl} /(\mathrm{bd}) 2($ when $\mathrm{a}>13.0 \mathrm{~cm}$ for $10 \mathrm{~cm}$ specimen $)$

$\mathrm{fb}=3 \mathrm{pa} /(\mathrm{bd}) 2($ when $\mathrm{a}<13.3 \mathrm{~cm}$ but $>11.0 \mathrm{~cm}$ for $10.0 \mathrm{~cm}$ specimen.)

Where,

$\mathrm{a}=$ the distance between the line of fracture and the nearer support, measured on the center line of the tensile side of the specimen

\section{DEPT. OF CIVIL ENGINEERING ISLAMIAH} INSTITUTE OF TECHNOLOGY B'LORE 46

$\mathrm{b}=$ width of specimen $(\mathrm{cm}) \mathrm{d}=$ failure point depth $(\mathrm{cm}) 1=$ supported length $(\mathrm{cm}) \mathrm{p}=\max . \operatorname{Load}(\mathrm{kg})$

\section{OBJECTIVES AND SCOPE OF PRESENT INVESTIGATION}

The construction of concrete walls in buildings has been gaining importance over the years. These walls may be used as load bearing walls acting as integral part of the structure with cast in-situ concrete or precast wall panels. The use of concrete walls in structures is due to the availability of high strength and high performance concrete at present. Use of thinner concrete walls in the structure not only improves the structural performance, but also increases the net available floor area of the building. Slender walls are susceptible to buckling apart from direct crushing. This is not a design criteria in the conventional concrete member. Jeung-Hwan Doh in 2002 has made a report on the behaviour of slender wall panels under the impact of direct load and buckling. His work is on conventional plain concrete of normal and high strength.

Fibre Reinforced Concrete is another special concrete which can be considered for concrete walls to enhance its performance. At present, latest generation concrete, SCC, is also used for constructing wall panels. Fibre Reinforced SCC (FRSCC) is another viable alternative to conventional concrete considering all the advantages of FRSCC. However, it is observed that very little work is reported on FRSCC walls. Keeping the research gap in view, an attempt is made 12 in this study to investigate the behaviour of SCC and FRSCC wall panels under crushing and buckling. 
The Stress-Strain behaviour is one parameter that is very useful in predicting the behaviour of the material when it is subjected to different load systems. The studies on Stress- Strain behaviour not only helps in determining many physical properties but also helps in accurately predicting the same material in the form of different structural components. Keeping this in view, studies on the behaviour of FRSCC is also made as an integral component of the present investigations. Considering the gaps in the available literature, the present investigations are aimed at producing standard grade (M60) FRSCC wall panels with Glass Fibers, consisting of a mixture of Glass and study their structural behaviour.

The different phases of the present research work are as follows: Phase I: Development of M60 grade SCC and obtaining its fresh and hardened properties. Phase II: Development of Glass Fibre Reinforced SCC (GFRSCC), and study of fresh and hardened properties Phase III: Stress-Strain behaviour of the above FRSCC under unconfined and confined states and obtaining the parameters like Modulus of Elasticity, Ductility Factors and Plasticity Index, and developing mathematical models. Phase IV: Study the structural behaviour of SCC and FRSCC wall panels under axial and eccentric loadings and comparing the ultimate load carrying capacities using the principles of strength of materials. Further, the ultimate loads for full scale wall panels are predicted using model analysis techniques. 